\title{
EFEITO DAS PROPRIEDADES ESTRUTURAIS DO SUBSTRATO SOBRE AS CONDIÇÕES TÉRMICAS EM UM BIORREATOR DE FERMENTAÇÃO SÓLIDA
}

\author{
F. P. CASCIATORI ${ }^{1 *}$, P. A. CASCIATORI ${ }^{2}$, J. C. THOMÉO ${ }^{1}$ \\ ${ }^{1}$ Universidade Estadual Paulista, Departamento de Engenharia e Tecnologia de Alimentos \\ ${ }^{2}$ Universidade Estadual Paulista, Departamento de Química e Ciências Ambientais \\ e-mail: fernandacasciatori@yahoo.com.br
}

\begin{abstract}
RESUMO
O presente trabalho teve como objetivo avaliar o efeito das propriedades estruturais do substrato sobre as condições térmicas em biorreatores de fermentação em estado sólido (FES) em leito empacotado, mediante a geração de calor em decorrência das atividades metabólicas do fungo. A FES é um processo biotecnológico viável para o suprimento de enzimas hidrolíticas à cadeia de produção de etanol de segunda geração (2G), alternativa energética sustentável, mas encontra barreiras na carência de estudos de engenharia que viabilizem a operação dos biorreatores em escala industrial. $O$ fungo termófilo Myceliophthora thermophila I-1D3b foi cultivado em diferentes substratos em biorreator de leito empacotado encamisado com 7,62 cm de diâmetro interno e 0,4 $\mathrm{m}$ de comprimento. Os substratos empregados foram uma mistura de fibras de bagaço de cana e farelo de trigo $(7: 3 \mathrm{~m} / \mathrm{m})$, farelo de trigo puro e uma mistura de bagaço de cana em pó e farelo de trigo $(1: 1 \mathrm{~m} / \mathrm{m})$. As temperaturas do ar percolante e da camisa foram mantidas a $45^{\circ} \mathrm{C}$ e a vazão de ar foi $60 \mathrm{~L} / \mathrm{h}$. Ao longo da fermentação, observou-se elevação de temperatura expressiva quando do emprego de farelo de trigo puro e da mistura de bagaço de cana em pó e farelo de trigo como substratos, denotando que a baixa porosidade do leito comprometeu a remoção de calor do interior da matriz sólida nesses casos. Quando do cultivo em substrato contendo fibras de bagaço de cana, meio mais poroso, o crescimento do fungo foi bem distribuído pela matriz e a elevação de temperatura foi desprezível, mantendo-se a condição térmica desejável no biorreator.
\end{abstract}

\section{INTRODUÇÃO}

Neste momento em que o desenvolvimento tecnológico de uma matriz energética limpa e renovável é estratégico para o Brasil, as enzimas celulolíticas chamam atenção da comunidade científica e industrial, tendo em vista sua aplicação na hidrólise de materiais lignocelulósicos, resíduos da agroindústria, na cadeia de produção do etanol de segunda geração (2G). Dentre os rejeitos agroindustriais disponíveis, se destaca o bagaço da cana-de-açúcar, resíduo da produção do etanol de primeira geração e constituído por celulose, hemicelulose e lignina, sendo potencial fonte de açúcares fermentescíveis (PANDEY et al., 2000).

A produção do etanol de segunda geração envolve pré-tratamento do bagaço, hidrólise da celulose e fermentação dos açúcares liberados. É conveniente que a hidrólise seja enzimática, com baixo gasto energético, alta especificidade pelo substrato e não geração de compostos indesejáveis. As principais enzimas envolvidas neste processo são as celulases, bioproduto de interesse deste trabalho. Todavia, a hidrólise enzimática é 
lenta e tem como uma das principais barreiras processos eficientes e viáveis de produção de enzimas a custo que não inviabilize seu uso (MISHIMA et al., 2006). A alternativa aqui estudada para a produção de celulases é a fermentação em estado sólido (FES), processo que permite obter tais enzimas também a partir de rejeitos agroindustriais, o que pode ser tanto econômica quanto ambientalmente interessante.

A fermentação em estado sólido (FES) consiste no crescimento de microrganismos sobre partículas sólidas úmidas, em situações nas quais o espaço entre as partículas contêm uma fase gasosa contínua e a água pode estar impregnada nas partículas ou formar um fino filme sobre elas (MITCHELL; KRIEGER; BEROVIC, 2006). Devido às atividades de água mais baixas na FES, os microrganismos que mais se adaptam a esse cultivo são os fungos filamentosos, dentre os quais os termofílicos se destacam por produzirem enzimas mais termoestáveis, característica interessante do ponto de vista industrial da produção do bioetanol. No entanto, a técnica de produção de celulases por FES ainda está em desenvolvimento, não se encontrando biorreatores disponíveis comercialmente para tal finalidade.

Tendo em vista que os biorreatores de leito empacotado têm baixo custo e facilidade de construção e operação, estes podem ser interessantes para a produção de enzimas hidrolíticas fúngicas por FES, mas tais fermentadores estão sujeitos ao problema de sobreaquecimento devido à geração de calor metabólico ao longo do processo. A dissipação do calor gerado dependerá de fatores como as condições operacionais (vazão e umidade relativa do ar), a geometria do equipamento (dimensão e formato) e o tipo de substrato utilizado (porosidade, condutividade térmica, formato e dimensão das partículas).

É bem conhecido que a porosidade $(\varepsilon)$ de um leito empacotado afeta diretamente a fluidodinâmica e as propriedades efetivas de transferência de calor e de massa dos meios porosos, tais como permeabilidade do leito, condutividade térmica e difusividade mássica efetivas (TSOTSAS, 2010). Portanto, uma matriz porosa ideal para biorreatores de FES deve suprir as necessidades nutricionais do microrganismo e ainda fornecer adequada estrutura física para a percolação de ar, a fim de garantir transferência eficiente dos gases respiratórios e facilitar a remoção do calor gerado metabolicamente.

Alguns autores já avaliaram o efeito das propriedades estruturais do substrato na FES. Kumar et al. (2003) cultivaram Aspergillus niger em bagaço de cana e farelo de trigo enriquecidos com melaço, tendo observado aglomeração nos leitos de farelo com $65 \%$ de umidade, enquanto leitos de bagaço de cana mantiveram estrutura porosa até $85 \%$ de umidade. Pandey et al. (1999) afirmam que a densidade de partícula regula a utilização do substrato pelo microrganismo a nível molecular; tamanhos de partícula pequenos interferem na respiração microbiana, levando a um crescimento fúngico deficiente; tamanhos de partícula grandes limitam a superfície disponível para o ataque microbiano. A densidade do leito também já mostrou afetar os rendimentos dos processos de FES. Dorta e Arcas (1998) estudaram o efeito da densidade de empacotamento no rendimento de esporos de Metarhizium anisopliae cultivado em mistura de farelo e casca de arroz, tendo observado uma significante redução da biomassa acumulada quando do aumento da densidade do leito.

Diante do exposto, o objetivo do presente trabalho foi avaliar o efeito da porosidade de diferentes substratos (farelo de trigo puro, $\mathrm{FT}_{\text {puro, }}$ e farelo de trigo, FT, misturado com bagaço de cana em fibras, $\mathrm{BC}_{\text {fibra }}$, e em pó, $\mathrm{BC}_{\mathrm{pó}}$ ) sobre as condições térmicas no interior de um biorreator de FES em leito empacotado, potencialmente aplicável à produção de enzimas celulolíticas. 


\section{MATERIAIS E MÉTODOS}

\subsection{Microrganismo e Substrato}

Foi empregado como agente fermentativo o fungo termófilo recentemente isolado Myceliophthora thermophila I-1D3b. Como substratos, foram empregados bagaço de cana (em fibras, $\mathrm{BC}_{\text {fibra, }}$ e em pó, $\mathrm{BC}_{\mathrm{pó}}$, tamanhos de partícula 3 e $0,84 \mathrm{~mm}$, respectivamente) e farelo de trigo (FT, tamanho de partícula 0,44 $\mathrm{mm}$ ). A composição da mistura de fibras de bagaço de cana e farelo de trigo seguiu a proporção de $\mathrm{BC}_{\text {fibra: }}: \mathrm{FT} 7: 3 \mathrm{~m} / \mathrm{m}$; para a mistura de bagaço de cana em pó e farelo de trigo, a proporção foi de $\mathrm{BC}_{\mathrm{pó}}: \mathrm{FT} 1: 1 \mathrm{~m} / \mathrm{m}$.

Os substratos secos e a solução salina nutriente foram esterilizados em autoclave. Posteriormente, substratos foram inoculados com a suspensão de esporos e umidificados com solução nutriente até atingirem a umidade adequada para a fermentação. Para o meio contendo fibras, a umidade inicial foi de $75 \%$ (base úmida, b.u.). Para farelo de trigo e farelo de trigo com bagaço de cana em pó, a umidade inicial foi $65 \%$ (b.u.). Por fim, os substratos foram homogeneizados e então empacotados no leito.

\subsection{Fermentação em Biorreator de Leito Empacotado}

Os ensaios fermentativos foram realizados num biorreator cilíndrico de leito empacotado encamisado construído de forma modular em aço inox, composto por módulos com diâmetro interno $7,62 \mathrm{~cm}$ e comprimento $10 \mathrm{~cm}$ cada, de modo que pôde atingir $0,4 \mathrm{~m}$ de comprimento pela adição de 4 módulos consecutivos.

As temperaturas do ar e da camisa foram $45{ }^{\circ} \mathrm{C}$ e a duração da fermentação foi de 96 horas. A taxa de aeração foi de $60 \mathrm{~L} / \mathrm{h}$. A fim de se acompanharem as condições térmicas no interior do biorreator durante o processo, termopares tipo $\mathrm{T}$ foram instalados ao longo do comprimento do equipamento para registro das temperaturas atingidas no centro do leito. Os sinais elétricos dos sensores foram registrados por sistema de aquisição de dados COMPAQ-DAQ ${ }^{\circledR}$ gerenciado por rotina em Labview ${ }^{\circledR}$ (National Instruments, Austin, USA).

\section{RESULTADOS E DISCUSSÃO}

Nas Figuras 1a a 1c, são apresentados, respectivamente, os perfis de temperatura ao longo do processo fermentativo nos substratos $\mathrm{BC}_{\text {fibra: }}: \mathrm{FT} \quad 7: 3 \mathrm{~m} / \mathrm{m}, \mathrm{FT}_{\text {puro }}$ e $\mathrm{BC}_{\mathrm{pó}}: \mathrm{FT}$ 1:1 $\mathrm{m} / \mathrm{m}$, respectivamente.

Em BC:FT 7:3 m/m (Figura 1a), as temperaturas registradas atingiram valor máximo de $47{ }^{\circ} \mathrm{C}$, valor muito próximo à temperatura ideal de processo, indicando que o sobreaquecimento devido à geração de calor metabólico foi desprezível e que a condição térmica no interior do biorreator se manteve dentro da faixa desejável.

Por outro lado, quando do cultivo em $\mathrm{FT}_{\text {puro }}$ (Figura 1b) e na mistura $\mathrm{BC}_{\mathrm{poo}}: \mathrm{FT} 1: 1$ $\mathrm{m} / \mathrm{m}$ (Figura 1c), a temperatura atingiu $52{ }^{\circ} \mathrm{C}$, denotando que o sobreaquecimento no leito foi acentuado quando do cultivo nessas matrizes de menor porosidade.

Como o farelo de trigo é considerado um substrato ideal para a FES, por conta de fornecer fontes bem balanceadas de carbono facilmente disponível, além de nitrogênio e fósforo (PANDEY, 2003), se poderia cogitar que o cultivo do fungo neste substrato teria induzido a uma taxa mais intensa de geração de calor metabólico devido ao crescimento mais facilitado e acelerado, o que por sua vez poderia ter sido o fator determinante para $\mathrm{o}$ sobreaquecimento. No entanto, tendo-se observado que o sobreaquecimento ocorreu tanto para cultivo em $\mathrm{FT}_{\text {puro }}$ quanto em $\mathrm{BC}_{\mathrm{po}}: \mathrm{FT} 1: 1 \mathrm{~m} / \mathrm{m}$, outro substrato com baixa porosidade mas com composição nutricional menos favorável, concluiu-se que o aumento de temperatura no biorreator quando do emprego de matriz com baixa porosidade está 
mais associado aos fenômenos de transporte envolvidos no processo que à composição nutricional do substrato.

Figura 1 - Perfis de temperatura ao longo do processo fermentativo nos substratos: (a) $\mathrm{BC}_{\text {fibra }}: \mathrm{FT} 7: 3 \mathrm{~m} / \mathrm{m}$; (b) $\mathrm{FT}_{\text {puro }} ;$ (c) $\mathrm{BC}_{\text {pó }}: \mathrm{FT}$ $1: 1 \mathrm{~m} / \mathrm{m}$.

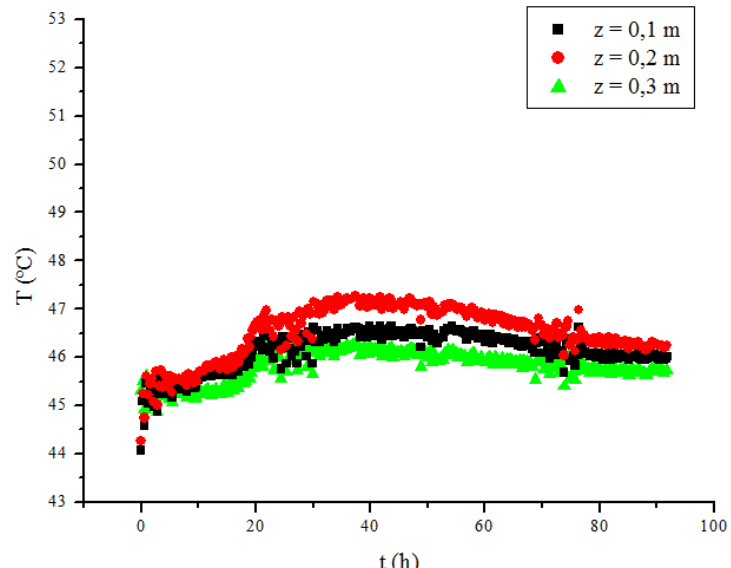

(a)

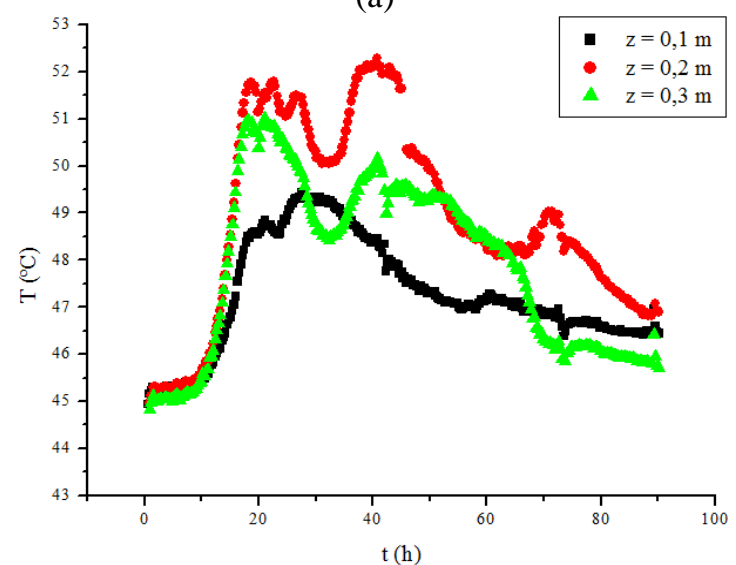

(b)

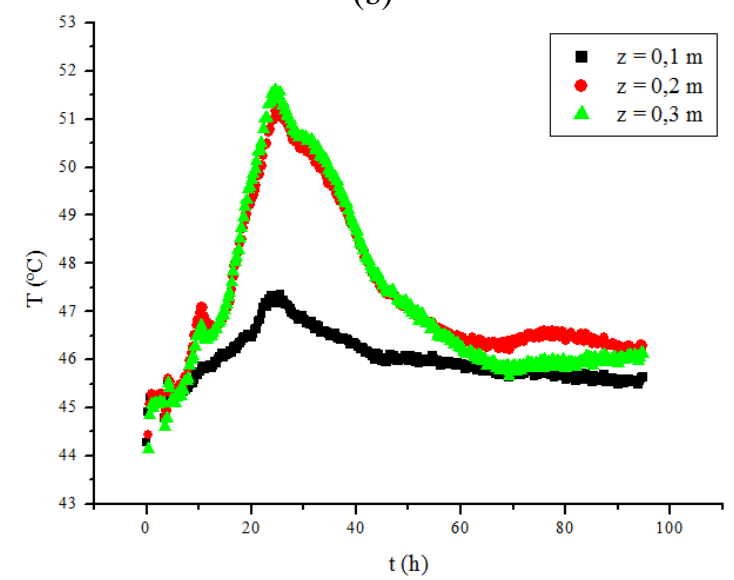

(c)
Casciatori et al. (2014) mostrou que leito composto por partículas de $\mathrm{FT}_{\text {puro }}$ é mais denso, compacto e menos poroso que leitos compostos por $\mathrm{BC}_{\text {fibra }}: \mathrm{FT} \quad 7: 3 \mathrm{~m} / \mathrm{m}$. Em termos de fluidodinâmica, infere-se que o ar encontrou maior dificuldade para percolar o meio compacto, de modo que deve ter escoado preferencialmente através dos canais na região da parede, zona de máxima porosidade (ZOTIN, 1985). Assim, a remoção do calor gerado por convecção pode ter sido prejudicada na região central do leito, ocasionando a elevação de temperatura.

De acordo com Casciatori et al. (2013), a condutividade térmica efetiva na estagnação também é menor no leito de FT que no de BC, sendo os valores calculados iguais a $0,384 \mathrm{e}$ $0,444 \mathrm{~W} / \mathrm{m} / \mathrm{K}$, respectivamente, de modo que a remoção de calor por condução também foi prejudicada nos leitos não contendo as fibras de bagaço de cana.

Nas Figuras 2a a 2c, podem ser vistos os aspectos dos materiais ao final dos cultivos em BC $_{\text {fibra }}: F T$ 7:3 m/m, em FT $_{\text {puro }}$ e em $\mathrm{BC}_{\mathrm{poo}}:$ FT 1:1 m/m, respectivamente.

Pode-se notar que o fungo cresceu uniforme e homogeneamente distribuído em BC:FT 7:3 m/m (Figura 2a), ao passo que só se desenvolveu no contorno do meio poroso no caso do cultivo em $\mathrm{FT}_{\text {puro }}$ (Figura 2b), e alguns pontos sem crescimento também podem ser vistos no caso do cultivo em $\mathrm{BC}_{\mathrm{poo}}:$ FT 1:1 m/m (Figura 2c).

Esse resultado indica que, no caso do cultivo em meios com porosidade muito baixa, além de a temperatura ter se mantido favorável ao crescimento fúngico somente na região próxima da parede encamisada, o ar também deve ter escoado preferencialmente através dos canais formados no contato entre a matriz porosa e a parede do tubo (ZOTIN, 1985), dificultando também o suprimento de oxigênio e a remoção de gás carbônico no interior do leito. 
Figura 2 - Aspecto da matriz porosa fermentada

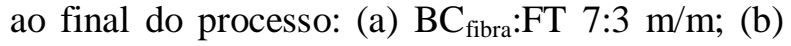
$\mathrm{FT}_{\text {puro }} ;$ (c) $\mathrm{BC}_{\mathrm{po}}: \mathrm{FT} 1: 1 \mathrm{~m} / \mathrm{m}$.

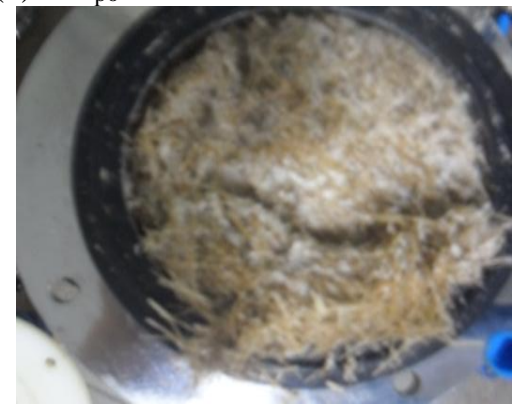

(a)

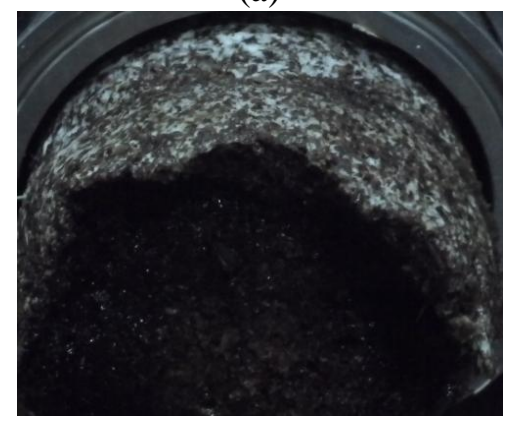

(b)

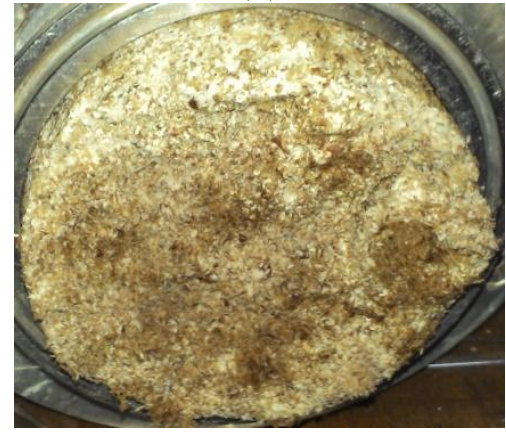

(c)

Portanto, os resultados do presente trabalho reforçam a hipótese de que a matriz porosa ideal para biorreatores de FES deve apresentar propriedades estruturais que facilitem os fenômenos de transferência de calor e de massa no interior do leito.

\section{CONCLUSÃO}

Tendo em vista os resultados obtidos, reitera-se a importância do emprego de substratos com alta porosidade para garantir a manutenção das condições térmicas ideais no interior do biorreator de FES em leito empacotado, bem como a transferência de oxigênio até o interior da matriz porosa. Sobretudo em se tratando da produção de enzimas de interesse industrial, evitar o sobreaquecimento do leito é essencial devido à termossensibilidade do bioproduto.

\section{NOMENCLATURA}

$\begin{array}{llc}\mathrm{m} / \mathrm{m} & \begin{array}{l}\text { Proporção massa por } \\ \text { massa }\end{array} & (-) \\ \mathrm{T} & \text { Temperatura } & \\ \mathrm{z} & \text { Posição axial } & { }^{\circ} \mathrm{C} \\ & & \mathrm{m}\end{array}$

\section{REFERÊNCIAS}

CASCIATORI, F. P.; LAURENTINO, C. L.; LOPES, K. C. M.; SOUZA, A. G.; THOMÉO, J. C. Stagnant Effective Thermal Conductivity of Agro-Industrial Residues for Solid-State Fermentation. International Journal of Food Properties, v. 16, p. 15781593, 2013.

CASCIATORI, F. P.; LAURENTINO, C. L.; TABOGA, S. R.; CASCIATORI, P. A.; THOMÉO, J. C. Structural Properties of Beds Packed with Agro-Industrial Solid ByProducts Applicable for Solid-State Fermentation: Experimental Data and Effects on Process Performance. Chemical Engineering Journal, v. 255, p. 214-224, 2014.

DORTA, B.; ARCAS, J. Sporulation of Metarhizium anisopliae in Solid-State Fermentation with Forced Aeration. Enzyme Microbial Technology, v. 23, p. 501-505, 1998.

KUMAR, D.; JAIN, V. K.; SHANKER, G.; SRIVASTAVA, A. Utilisation of Fruits Waste for Citric Acid Production by SolidState Fermentation. Process Biochemistry, v. 38, p. 1731-1738, 2003. 
MISHIMA, D.; TATEDA, M.; IKE, M.; FUJITA, M. Comparative Study on Chemical Pretreatments to Accelerate Enzymatic Hydrolysis of Aquatic Macrophyte Biomass used in Water Purification Processes. Bioresource Technology, v. 97, p. 21662172, 2006.

MITCHELL, D. A.; KRIEGER, N.; BEROVIC, M. Solid-State Fermentation Bioreactors: Fundamentals, Design and Operation. Berlin: Springer-Verlag, 2006.

PANDEY, A. Solid-State Fermentation. Biochemical Engineering Journal, v. 13, p. 81-84, 2003.

PANDEY, A.; SELVAKUMAR, P.; SOCCOL, C. R.; NIGAM, P. Solid-State Fermentation for the Production of Industrial Enzymes. Current Science, v. 77, p. 149163, 1999.

PANDEY, A.; SOCCOL, C. R.; NIGAM, P.; SOCCOL, V. T. Biotechnological Potential of Agro-Industrial Residues. I. Sugarcane Bagasse. Bioresource Technology, v. 74, p. 69-80, 2000.

TSOTSAS, E. Heat and Mass Transfer in Packed Beds with Fluid Flow. VDI Heat Atlas. Berlin: Springer-Verlag, 2010.

ZOTIN, F. M. Z. O efeito parede em colunas de recheio. 1985. 85p. Dissertação (Mestrado em Engenharia Química) Universidade Federal de São Carlos, São Carlos, 1985.

\section{AGRADECIMENTOS}

Os autores agradecem, pela concessão de bolsas e auxílio para desenvolvimento desta pesquisa, à Fundação de Amparo a Pesquisa do Estado de São Paulo (FAPESP) (processo $n^{\circ}$ 2011/07453-5; 2013/01756-1 e 2014/23453-3) e ao convênio FAPESP/ CAPES (proc. 2014/25183-3). 